\title{
Persistence of Mediterranean anaemia in Sicily
}

\author{
Maria Antonietta Romeo, Felicia Di Gregorio, Giuseppe Russo
}

\begin{abstract}
We report 40 cases of homozygous $\beta$ thalassaemia, aged between 3 and 24 months, who were observed between January 1990 and June 1996 at the Thalassaemia Centre, Paediatric Department, Catania University. A questionnaire was used to find out the parents' knowledge of their risk before the birth of the affected children and showed that the persistence of Mediterranean anaemia in Sicily was mainly because of the following reasons: (1) poor information (62.5\%), (2) laboratory error $(12.5 \%)$, (3) difficulty in the differential diagnosis of $\beta$ thalassaemia trait $(10 \%)$, and (4) not performing prenatal testing or selective abortion of an affected fetus (15\%).

We conclude that improved preventive measures at various medical and social levels can remove risk factors and so further reduce the incidence of Mediterranean anaemia in Sicily.

$(F$ Med Genet 1997;34:869-870)
\end{abstract}

Keywords: Mediterranean anaemia; $\beta$ thalassaemia; Sicily

Clinica Pediatrica

Università, University of Catania, Viale

Andrea Doria 6, 95125

Catania, Italy

M A Romeo

F Di Gregorio

G Russo

Correspondence to:

Dr Romeo.

Received 12 August 1996 Revised version accepted for publication 25 March 1997

In the last few years the improvement in health education as a result of premarriage information from Family Health Services and doctors, and genetic counselling to couples at risk from gynaecologists and paediatricians, together with the possibility of prenatal diagnosis, has prevented the birth of more than $50 \%$ of the 47 or so yearly expected cases of Mediterranean anaemia in the Sicilian population. ${ }^{1}$ According to Maggio et $a l^{2}$ the incidence of Cooley's anaemia has stabilised since 1985

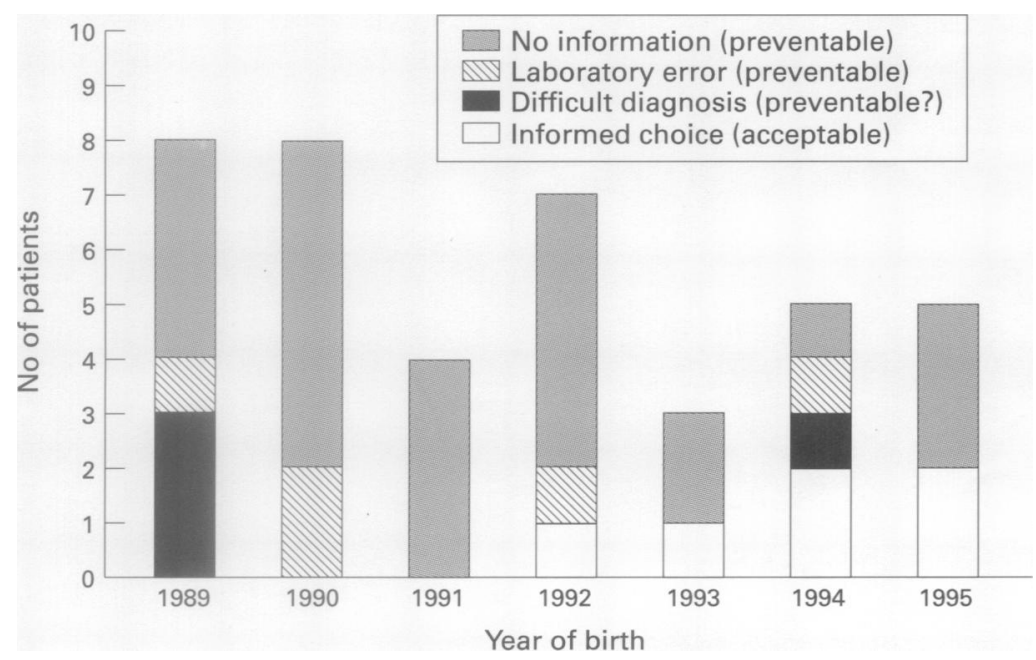

Figure 1 Distribution of the thalassaemic patients per birth year and reasons for the persistence of Mediterranean anaemia in Sicily. because of the heterogeneous distribution of the $\beta$ thalassaemia gene and the reduced efficacy of the screening programmes in peripheral centres.

Between January 1990 and June 1996, we observed 40 cases of homozygous $\beta$ thalassaemia, aged between 3 and 24 months, at the Thalassaemia Centre, Paediatric Department, Catania University. The distribution of our patients per birth year is shown in fig 1 . The sample represents a large proportion of the homozygous $\beta$ thalassaemia children born in east Sicily in this period, because about $75 \%$ of thalassaemic subjects in this area are diagnosed in our department. However, the exact number of affected newborns per year is difficult to estimate, because the last regional report was in $1990 .^{12}$

A questionnaire was used to find out the parents' knowledge of their risk before the birth of the affected children and showed that the persistence of Mediterranean anaemia in Sicily was mainly because of the following reasons.

(1) Even today poor information is the main cause of failure in prevention programmes. In fact, $25(62.5 \%)$ parent couples did not know about thalassaemia or related problems before conceiving the child. Excluding two couples who had immigrated from countries with a high incidence of $\beta$ thalassaemia (Albania and Mauritius), the couples in this group lived in peripheral towns and had received genetic counselling only in the last months of pregnancy or after the birth of the affected child. As a result of retrospective information, six of these couples had prenatal tests performed during subsequent pregnancies.

(2) In five cases $(12.5 \%)$ the birth of a child with thalassaemia major was the result of laboratory error. In fact, the $\beta$ thalassaemia trait had been diagnosed in only one parent before conception of the child. Laboratory investigations carried out in our department after the birth of the affected child showed typical $\beta$ thalassaemia trait with microcytosis and high $\mathrm{Hb}$ $\mathrm{A}_{2}$ levels in both parents. This finding suggests the need to carry out screening for thalassaemia and haemoglobinopathies only in experienced laboratories.

(3) The parents of four other children (10\%) had also undergone screening for $\beta$ thalassaemia before pregnancy. However, the heterozygous state had been detected in one and ruled out in the other parent, who had mild microcytosis and normal or borderline $\mathrm{Hb} \mathrm{A}_{2}$ levels. These mild cases were interpreted as $\alpha$ thalassaemia carriers, but postnatal DNA analysis of the $\beta$ gene showed the presence of the IVSI-nt6 mutation, associated with $\alpha$ thalassaemia trait in two cases and with mild 
Table 1 Preventive measures to reduce the incidence of Mediterranean anaemia

\begin{tabular}{ll}
\hline Risk factors & Measures to remove risk \\
\hline No or poor information & $\begin{array}{l}\text { Intensive educational programmes aimed at all Sicilian people to inform } \\
\text { about thalassaemia and detect couples at risk }\end{array}$ \\
Non-detection of typical $\beta$ thalassaemia carrier & $\begin{array}{l}\text { Screening in experienced laboratory } \\
\text { Special laboratory investigations }\end{array}$ \\
Non-detection of atypical $\beta$ thalassaemia carrier & Splations \\
\hline
\end{tabular}

iron deficiency in another. Atypical forms linked to mild $\beta$ thalassaemia gene expression are frequent in the Sicilian population and can hinder differential diagnosis of $\beta$ thalassaemia trait. Moreover, the identification of $\beta$ thalassaemia carriers can prove more difficult because of the interaction of genetic or acquired conditions, such as $\alpha$ thalassaemia, $\delta$ thalassemia, or iron deficiency anaemia, capable of reducing $\mathrm{Hb} \mathrm{A}_{2}$ to normal or borderline levels. ${ }^{3}$ Therefore, when a carrier's partner shows some haematological abnormality the couple should be referred to a specialist laboratory ${ }^{4}$ for additional diagnostic investigations, such as determination of $\alpha /$ non- $\alpha$ ratio by globin chain synthesis in vitro or DNA analysis of the $\beta$ gene.

(4) Six couples (15\%) knew their risk before beginning pregnancy. Three of them did not request prenatal diagnosis while the other three couples chose to continue the pregnancy of the homozygous fetus diagnosed by prenatal test- ing. These reproductive choices of informed couples (one of them had already had a child with thalassaemia major) are obviously comprehensible and justified when genetic counselling is, as it must be, non-coercive.

We conclude that improved preventive measures at various medical and social levels can remove the risk factors reported in table 1 and so further reduce the incidence of Mediterranean anaemia in Sicily, as has occurred in other Italian regions. ${ }^{5}$

1 Giambelluca S, Gentile AM, Pinzone F, Schilirò G. Thalassaemia strategy in Sicily. Lancet 1992;339:179-80.

2 Maggio A, Caronia F, Orlandi F. Prenatal diagnosis of haemoglobinopathies in Sicily. Lancet 1992;339:1361-2.

3 Cao A. 1993 William Allan Award Address. Am f Hum Genet 1994;54:397-402.

4 Modell B. Genetic screening for ethnic minorities. BMF 1990;301:290.

5 Bianco I, Graziani B, Lerone M, et al. Prevention of Mediterranean anaemia in Latium, Italy, today. $₹$ Med Genet 1994;31:86. 